\title{
Identification of dynamic capabilities in open innovation
}

\author{
Edson Rodrigues de Aro \\ Faculdade de Administração e Ciências Contábeis, \\ Univerdade Federal de Mato Grosso, Cuiaba, Brazil, and \\ Gilberto Perez \\ Universidade Presbiteriana Mackenzie, São Paulo, Brazil
}

\section{Dynamic capabilities in innovation}

Received 15 October 2019

Revised 12 July 2020

24 September 2020

3 November 2020

Accepted 15 December 2020

\begin{abstract}
Purpose - This study aims to understand the interaction between capabilities inherent in open innovation and dynamic capabilities (sensing, seizing and transforming) as a source of competitive advantage.

Design/methodology/approach - Qualitative method and grounded theory were used as guidelines for data collection and analysis.

Findings - The study identifies a set of capabilities in the practice of open innovation related to dynamic capabilities, which indicates the importance of developing dynamic capability in the strategic management of internal and external knowledge in the company.

Research limitations/implications - The number of interviewees approached herein do not allow generalizations, but the use of grounded theory through various strategies of data collection in the interviews allowed the triangulation of the data, increasing the credibility, validity and quality of the research.

Originality/value - This study presents capabilities identified in open innovation and their relationship with dynamic capabilities, identifying the importance of the dynamic capability in the strategic management of internal and external knowledge in the company as a source of competitive advantage.
\end{abstract}

Keywords Open innovation, Dynamic capabilities, Grounded theory

Paper type Research paper

\section{Introduction}

To obtain resources in open innovation, capabilities need to be understood and incorporated by the company in the search for competitive advantage. One way the company has used to obtain resources is the practice of open innovation as a strategic alternative to gain competitive advantage through internal and external collaboration to identify opportunities and develop new markets (Chesbrough, 2012; Bogers, Chesbrough, \& Moedas, 2018). Thus, understanding dynamic capabilities in open innovation can be a source of competitive advantage (Teece, 2018).

In this context, understanding the different levels of analysis - at the enterprise level, such as structures and processes and individual levels such as individual capabilities facilitate the implementation or interdependence of open innovation between organizations

(c) Edson Rodrigues de Aro and Gilberto Perez. Published in Innovation and Management Review. Published by Emerald Publishing Limited. This article is published under the Creative Commons Attribution (CC BY 4.0) licence. Anyone may reproduce, distribute, translate and create derivative works of this article (for both commercial and non-commercial purposes), subject to full attribution to the original publication and authors. The full terms of this licence may be seen at http:// creativecommons.org/licences/by/4.0/legalcode

This paper forms part of a special section "Dynamic capabilities, entrepreneurship and innovation: exploring different levels of analysis", guest edited by Adriana Takahashi and Marcos Correa.

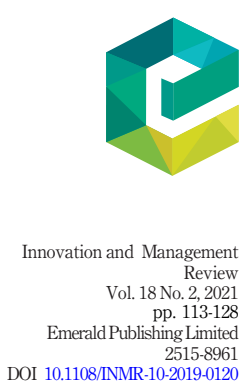


INMR

18,2

and various stakeholders in an innovation ecosystem scenario (Bogers et al., 2016). Considering these levels of analysis, organizational and dynamic capabilities are jointly developed in simple and complex routines in the form of dynamic package (Peteraf, Di Stefano, \& Verona, 2013); hence, the understanding of a company's critical capabilities to manage the knowledge that comes internally and externally in open innovation practices are necessary (Lichtenthaler \& Lichtenthaler, 2009).

Thus, there is little clarity as to the capabilities developed in the practice of open innovation and its relationship with dynamic capabilities in strategic management literature. Thus, it is argued that in the practice of open innovation capabilities are developed and contribute to the strengthening of dynamic capabilities to manage internal and external knowledge as a source of competitive advantage.

Based on these considerations, we aim to answer the following research question: How do capabilities in the practice of open innovation relate to dynamic capabilities? To answer this question, we must understand the capabilities related to the practice of open innovation with dynamic capabilities (sensing, seizing and transforming) as a source of competitive advantage.

To increase the understanding on these phenomena (open innovation and dynamic capabilities) through our study, qualitative method and grounded theory were used, according to the criteria proposed by Charmaz (2009). The practice of open innovation and capability development in the companies $3 \mathrm{M}$ Brazil and Natura were chosen as units of analysis. We expect our study to contribute to contemporary innovation literature published in the journal Innovation and Management Review (INMR) by understanding the capabilities developed in the practice of open innovation, expanding the discussions of Teece (2020) on dynamic capabilities, approaching the findings of Öberg and Alexander (2018) and Bogers, Chesbrough, Heaton, and Teece (2019) on open innovation, and exploring Lichtenthaler and Lichtenthaler's (2009) research on capabilities in open innovation for the management of internal and external knowledge in the innovation process.

This paper is organized as follows. Section 2 brings the discussions in literature on dynamic capabilities and open innovation. Section 3 approaches the methodological procedures adopted in this study. Section 4 brings the discussion of the results, and, finally, in Section 5 we present our final remarks and suggestions for future research.

\section{Literature review}

\subsection{Dynamic capability and open innovation}

Literature on dynamic capabilities has been developed according to two distinct aspects that seek to explain how companies achieve and sustain competitive advantage. The first strand, from the seminal article by Teece, Pisano, and Shuen (1997), considers that dynamic capabilities are relevant only for organizations operating in highly dynamic environments; the other strand comes from the article by Eisenhardt and Martin (2000) and defends that dynamic capabilities are also important for organizations that operate in moderately dynamic environments.

To understand dynamic capabilities, we present the following concepts, definitions, characteristics and elements discussed in strategic management literature. For Eisenhardt and Martin (2000), dynamic capabilities are used as specific resources in the process of integrating, reconfiguring and obtaining resources to match and even create a market change. For Denford (2013), dynamic capabilities are used by companies to integrate, build and reconfigure their organizational capabilities and are based on knowledge in three dimensions - internal/external source, focus on exploration/exploitation and combinatorial capability. According to the understanding of Dixon, Meyer, and Day (2014), dynamic capabilities are fundamental to foster organizational transformations and are identified in the dynamic capability of adaptation 
related to exploration routines, implementation and reconfiguration of resources and dynamic capability of innovation related to the creation of new capabilities through exploration processes and creation of paths.

Teece $(2007,2018)$ ranked in three components: sensing, seizing and transforming. In the sensing process, scanning, learning and interpreting activities are identified, which allows access to information and knowledge that can create opportunities (Dobelin \& Galina, 2019). The organization depends on individual creativity and is based on organizational processes of search, interpretation and creation. Therefore, we seek the identification, development, co-development and evaluation of threats and technological opportunities in relation to customer needs (Teece, 2007, 2018).

In seizing, companies seize what was obtained during sensing activities and represent the company's ability to respond to the environment (Dobelin \& Galina, 2019). Thus, by detecting a new technological or market opportunity, it should be capitalized through new products, processes, or services. This almost always requires investments in development and marketing activities, mobilization of resources to meet needs and opportunities and capturing value. When making investments, it is necessary to create strategies around investment decisions, set the time, increase the advantages of return and leverage products and services from one application to another (Teece, 2007).

In the transforming process, the organization seeks continuous renewal, that is, transformation or change (Teece, 2007). This component seeks to help the organization to configure the organizational culture to accept high levels of internal change through decentralization and flexibility and implementation of modern techniques of human resources, knowledge management and learning mechanisms (Dobelin \& Galina, 2019).

In this context, dynamic capabilities relate to complex routines and organizational mechanisms, or in simple routines and management mechanisms. Both are active in the company sequentially or simultaneously in the form of dynamic packages and it is necessary to have a complete and interconnected view as a whole to understand dynamic capabilities (Peteraf et al., 2013).

Bulgacov and Takahashi (2019) highlight that work routines and practices are the result of a set of capabilities that, through mechanisms, facilitate or not the conditions to continuously create capabilities. According to the authors, the appropriate combination between organization performance through processes and routines and its relationship with suppliers, customers, and other actors in the environment is at the heart of the dynamic capabilities' proposal. However, this ability to "feel", "grasp", "transform" and "reconfigure" remains unexplored, and the understanding of micro-foundations are sources of competitive advantage (Nayak, Chia, \& Canales, 2019).

Thus, since the presentation of the concept of dynamic capability attributed to Teece et al. (1997), the authors began to explore and point out alternatives to open innovation so that companies could expand and innovate their business model adapting to the environment using networks, alliances and partnerships as a way to meet current and future needs (Teece, 2018).

Thus, discussions on capabilities in open innovation have been around the modes and mechanisms of open innovation from an external and internal perspective (Bogers et al., 2016; Peris-Ortiz, Devece-Carañana, \& Navarro-Garcia, 2018). The challenge to be faced by companies is to understand ways to manage the process of search, selection and implementation and becomes a problem for learning and developing management skills (Tidd \& Bessant, 2015).

Chesbrough and Bogers (2014, p. 17) redefine open innovation as "a process of distributed innovation based on knowledge flows purposely managed by organizational boundaries", 
INMR

18,2

which resides at the organization level. Bogers et al. (2016) point out that in open innovation one must identify elements at different levels of analysis such as intraorganizational, organizational, extra organizational, interorganizational, industry, regional innovation system and society. For the authors, these elements are found at organizational levels, such as structures and processes, and individual levels, such as individual capabilities to facilitate the implementation or interdependencies of open innovation between organizations and various stakeholders in an innovation ecosystem scenario.

Öberg and Alexander (2018) point out that these links among levels are related to the search for relationships and collaboration, market path and shared activities, with degrees of formalization and levels of knowledge among the actors; the consideration of knowledge management criteria and management strategies in different dimensions of openness is very relevant.

Lichtenthaler and Lichtenthaler (2009) analyzed exploration, exploitation and knowledge retention within and outside the boundaries of a company that propose a capability-based structure for open innovation from the identification of knowledge capabilities as critical capabilities of a company to manage internal and external knowledge in innovation processes. This knowledge management capability is understood by the authors as a dynamic capability that reconfigures and realigns knowledge capabilities over time.

Öberg and Alexander (2018) point out some relevant open innovation capabilities, such as creation, negotiation, relationship, cooperation, collaboration and interaction in product development with their partners. However, it is necessary to have the ability to translate and assimilate the flow of knowledge generated for transferring from and sharing by the organization.

So, as Bogers et al. (2019) claim, dynamic capabilities are needed to focus on specific attributes related to leveraging and improving internal capabilities by boosting the business model itself through open innovation from the inside out or exploring a new business model through open innovation from the outside in.

Teece (2020) claims that open innovation and dynamic capabilities reinforce one another. For the author, open innovation enriches the company's knowledge base and its ability to detect and grasp transformations in the company's internal resources. Thus, the author points out that strong dynamic capabilities allow effective practices of open innovation.

\section{Methodological procedures}

The research aimed to understand the relationship between the capabilities related to the practice of open innovation and dynamic capabilities (sensing, seizing and transforming) as a source of competitive advantage. For the design of the research, a set of procedures and techniques proposed by Charmaz (2009) was developed through qualitative research and guidelines of grounded theory. Grounded theory was used because it is a qualitative research method that seeks to create conceptual schemes in the development of new categories established sequentially and systematically and use of the comparative method for analysis of the collected data sets.

The unit of analysis in this study was centered on the practice of open innovation by the companies $3 \mathrm{M}$ Brazil and Natura. Despite operating in different industrial sectors, these companies were chosen for demonstrating in public and private disclosures and in specialized segments the practice open innovation. The company $3 \mathrm{M}$ Brazil describes its understanding of open innovation on its website as follows:

The concept of collaboration is so strong at 3M that it goes beyond the company's borders and covers the relationship we establish with partners, clients, research centers, government entities, universities, startups, investors and others. It's what's called Open Innovation [ . . ] (3M, 2016, Brazil). 
Natura describes its understanding of open innovation on its website based on one of its products - Natura Campus - as follows:

Through Natura Campus, we work with open innovation sharing challenges with the scientific community in Brazil and abroad. This means that, in addition to scientists and internal research involving research and development, our business is strongly linked to partnerships with scientific institutions in Brazil and the world to develop new concepts, methodologies, products and processes [... . (Natura, 2016).

In this study, the in-depth interview was adopted as a means for data collection, which was conducted through a semi-structured script with standardized and appropriate open questions. Subsequently, we accomplished the process of initial, focused and theoretical coding according to information obtained from the interview; the data collection and analysis occurred from May to October 2016.

To increase the credibility, validity and quality of the research, an interview script was used in all stages with different data collection strategies. The questions and topics were based on the review of preliminary literature and developed from a validation matrix.

The interviews were conducted at three different moments with the managers of the companies $3 \mathrm{M}$ Brazil and Natura, as shown in Table 1 (initial coding), Table 2 (focused coding) and Table 3 (theoretical coding). In the initial coding phase, the managers interviewed in each company, in May 2016, were supposed to answer 13 questions, as shown in Table 1.
Source: Research data

\section{Dynamic capabilities in open innovation}

Table 1.

Respondents and questions 


\section{INMR}

18,2

Company Interviewed

\begin{tabular}{|c|c|c|}
\hline Natura & $\mathrm{E} 2 \mathrm{Na}$ & Administration and Innovation Networks Manager \\
\hline Natura & E2Na & Pro-innovation system manager \\
\hline Natura & $2 \mathrm{Na}$ & Manager for Partnership, intellectual property, and promotion of innovation \\
\hline Natura & $2 \mathrm{Na}$ & Strategic Planning Manager \\
\hline 3M & $23 M$ & Environment, Health and Product Safety Manager - EHS \\
\hline & $23 M$ & \\
\hline M & $E 23 M$ & Senior Laboratory S \\
\hline 1 & \multicolumn{2}{|c|}{$\begin{array}{l}\text { What is your company's strategic approach that opens the door to an open innovation } \\
\text { opportunity? }\end{array}$} \\
\hline 2 & \multicolumn{2}{|c|}{$\begin{array}{l}\text { How does the ability to analyze trend building and strategy influence open innovation? Search } \\
\text { for signs and trends, strategic tuning? What capabilities beyond these are relevant? }\end{array}$} \\
\hline 3 & \multicolumn{2}{|c|}{$\begin{array}{l}\text { Is the ability to interpret resources that you have and do not have a capability that influences } \\
\text { the search for open innovation? Comment on this. }\end{array}$} \\
\hline 4 & \multicolumn{2}{|c|}{$\begin{array}{l}\text { Talk about the ability to map partners and interaction in the innovation ecosystem. Do you have } \\
\text { other relevant capabilities related to open innovation in this ecosystem? }\end{array}$} \\
\hline 5 & \multicolumn{2}{|c|}{$\begin{array}{l}\text { How does open innovation in the company's innovation ecosystem influence the development of } \\
\text { capabilities/skills? Can you name a few of the most relevant ones that have been developed? }\end{array}$} \\
\hline
\end{tabular}

Table 2.

Interview with the focus group at Natura and $3 \mathrm{M}$ Brazil

Source: Research data

\begin{tabular}{|c|c|}
\hline Company & Interviewed \\
\hline Natura & Network and relationship manager \\
\hline 1 & $\begin{array}{l}\text { Questions applied in the interviews } \\
\text { The study revealed some relevant capabilities in open innovation: ability to map market trends, } \\
\text { ability to map internal resources and partner mapping, interaction, and relationship ability in } \\
\text { the innovation ecosystem }\end{array}$ \\
\hline 2 & Comment on these capabilities \\
\hline 3 & Would you add others? \\
\hline Company & Interviewed \\
\hline $3 \mathrm{M}$ & Environment, Health and Product Safety Manager - EHS \\
\hline $3 \mathrm{M}$ & $\begin{array}{l}\text { E33M Senior Laboratory Specialist } \\
\text { Questions applied in the interviews }\end{array}$ \\
\hline 1 & $\begin{array}{l}\text { The study revealed some relevant capabilities in the practice of open innovation: Mapping and } \\
\text { updating trends in the market; Analysis and definition of trends and strategies; Mapping of } \\
\text { internal resources; Establishment of what to do openly; Mapping of potential partners; } \\
\text { Partnership establishments; Implementation of the partnership; Two-level interaction } \\
\text { monitoring; Technical - within the project and relational - inside and outside the project, and } \\
\text { Evaluation of the result of interaction and relationship in the partnership }\end{array}$ \\
\hline 2 & Comment on these capabilities \\
\hline 3 & Would you add others? \\
\hline
\end{tabular}

Table 3.

Individual interview at Natura and in duo at $3 \mathrm{M}$ Brazil

Source: Research data 
In the interviews, the participants' definitions regarding terms, situations and events were emphasized to explore their assumptions, their implicit meanings and tacit rules in the coding phases analyzed in Section (4.1).

After analyzing the data in the initial coding, we returned to the field research for a new data collection with more subjects, totaling seven managers, four in Natura and three in the company $3 \mathrm{M}$ Brazil. According to Charmaz (2009), in any study, questions can occur during the research, which leads the researcher to create new methods of data collection and to review previous ones. In this new data collection, we applied five questions of the semistructured interview, which were conducted in loco in June 2016, using as strategy the focus group in the focused coding phase, as shown in Table 2.

After analyzing the data in the focused coding according to Section (4.2), new questions were asked to the interviewees illustrated in Table 3, theoretical coding phase. At Natura, three questions were asked in September via Skype to one of the managers based on the initial encodings and focused on data saturation. In possession of the information answered by the manager of the company Natura and better understanding of the meanings about the necessary capabilities in the practice of open innovation, we carried out the last data collection with two managers of the company 3 M Brazil in October 2016 via Skype, in which three questions were applied, saturating the data in this last analysis of theoretical coding according to Section (4.3).

Thus, during the entire development of data collection and analysis in the coding phases, the NVIVO® V11 program was used to understand the codes that were used in the analysis of results.

\section{Analysis and discussion of results}

This section brings the results from the coding phases regarding the identification of the capabilities developed by the companies $3 \mathrm{M}$ Brazil and Natura in their open innovation practices.

\subsection{Initial encoding}

In the first stage, initial encoding, the transcriptions of the interviews with E13M and E1Na were read to identify the initial codes and their relationships. Table 4 indicates the eight codes and the relationship among them identified at this first moment; the narratives were used to better understand the meanings of these data. These codes and relationships show the capabilities that are developed by the companies $3 \mathrm{M}$ Brazil and Natura in their open innovation practices.

The interviewees E1Na and E33M indicate some capabilities that were developed in the company during the development of open innovation, among them: to seek signals and trends, to identify, organize and make investments to obtain return from megatrends, to identify problems, to deliver solution in megatrends and to have strategic harmony. In addition to these, one must have the ability to interpret internal resources that the company does and does not have, know the own organization and all its resources and to acknowledge one's own competence and ability to pursue new skills to identify innovation opportunities.

According to E13M, the company should be oriented to identify business opportunities that are likely to succeed, that generate value:

We always start with the business strategy and then, from the business strategy we see the opportunities, usually the business emphasizes a lot the need for innovation, and then the pace, differentiation, and guidelines. (E13M) 
INMR

18,2

120

Codes Relationships

Cod1: Analysis of trend and strategy construction

Cod2: Innovation ecosystem

Cod3: Investment and technological competence

Cod4: Culture, behavior, and communication Cod5: Combination of skills

Cod6: Open innovation as a complement to the innovation process

Cod7: Possible forms of relationships

Table 4. Initial codes (nodes) and their Cod8: Open innovation as a strategic alternative

Source: Research data
Search for signs and trends

Ability to interpret resources

Oriented to identify business opportunity

Strategic tuning

Ability to interact

Ability to map partners and opportunities

Ability to translate other companies' competencies into the enterprise model

Ability to talk in the innovation ecosystem

Ability to identify your core and new competencies

Complementary competence: people, technologies, or projects

Collaboration and learning

Establishment and construction of partnerships

Cooperation

Networks

Vendor, licensing, and contracts

Differentiation and speed of something complementary in the innovation process

The capabilities developed in the practice of open innovation arise from sources that include programs, universities, companies, suppliers, consultancies, consumer, sales channel, open innovation events and startups. The interviewee E1Na reports the need to identify capabilities to face some critical success factors and lessons in open innovation such as, "to clarify your goal, what you want to do openly, the reason why, have a clear strategy, and based on it you must define what you want to do more open, with whom you want to do it, and how to seek these partners, in addition to the 'support of senior management”".

Some lessons are pointed out in open innovation practices and the capabilities that must be created, such as the ability to learn that there is intelligence inside and outside the company and in this learning process value knowledge is generated:

The innovation ecosystem within the company must have a very large integration with the functions, understand how innovation is linked to the company's strategy, business strategy, investments, and everything else. I have to innovate for the end customer, I have to innovate in the business model, in the channel, and I do not innovate alone (E13M).

The interviewees E13M and E1Na highlight that the culture of practices and the culture of the environment contribute to the development of capabilities, which requires entrepreneurial behavior, collaboration, good communication, recognition, creative freedom and ethical inflexibility of both commercial and technical parties. For the interviewee, what happens with open innovation is that it is part of the innovation process, it has flows and processes that must be managed throughout the process, and it must be in accordance with the strategic planning.

This context corroborates the findings of Chesbrough and Bogers (2014, p. 17), who redefine open innovation as "a process of distributed innovation based on knowledge flows purposely managed by organizational boundaries". 
From the understanding of the narratives of the interviewees E13M and E1Na in this first stage of initial coding, the capabilities identified so far in the practice of open innovation opened will be deepened in the focused coding stage.

\subsection{Focused coding}

This stage aimed to identify in the narratives of the interviews with E23M and E2Na the capabilities developed in the practice of open innovation by these companies in a more targeted and selective way that relate to dynamic capabilities. For this verification, categories of capabilities necessary in the practice of open innovation were formed, which were identified by the researchers during the recursive process of analysis in the data collection phase of the initial coding (E1Na; E13M) and in-depth interviews in this stage of focused coding with (E2Na; E23M), who reported through their routines and management processes the identification of capabilities in the company. These capabilities in the practice of open innovation are confronted with the foundations advocated by Teece $(2007,2018)$ regarding the activities of sensing, seizing and transforming.

Therefore, the capabilities of mapping and updating trends in the market (Cat1), analysis of and setting trends and strategies (Cat2) and mapping of internal resources (Cat3) are understood as capabilities related to sensing activities.

4.2.1 Cat1 - capability to map and update market trends. This capability, according to the interviewees, is understood as an essential capability to succeed, because the company needs to choose its partners well, it needs to establish a few criteria; it is precisely from the mapping of internal resources that we establish what to look for, what to find and who will be the potential partners:

We have this concern that this mapping has to be done very carefully, because people tend to map to justify what they're already doing, and not to identify new trends, so these are the things that need to be taken care of in mapping (E2Na).

The E23M interviewee reports the company's experience in a project that related to the exchange of Banco Real's flag by Santander in 2011, and the creation of the company $3 \mathrm{M}$ Services, which demanded numerous partnerships to execute this project:

This experience generated a much broader look for the opportunity provided by the service sector, this specific experience is related to a project where we were partners with several companies and which has become a center that develops the competence of service offers, opening doors to various business divisions (E23M).

Therefore, for the respondents, having the ability to map trends in the market is an ability that the company must have to update itself to develop open innovation in the company. As Teece (2007) states, the organization depends on individual creativity and is based on organizational processes of search, interpretation and creation.

4.2.2 Cat2 - capability to analyze and define trends and strategies. This capability is reported by the interviewees as a relevant ability to identify, organize and make investments to obtain returns from megatrends, to identify problems and to deliver solution. An example can be verified in the narrative of E23M:

An automaker for urban mobility, this is a megatrend, what does this reflect on the automaker? Cars have to be more economic, you spend a lot of time in traffic jams, they need to provide more fun, etc. That's a thing for the car, and what about the citizen? What about the City Hall? It's something else. So, depending on each project, the same strand may have completely different needs. 
INMR

18,2

The definition of themes derived from the market generates the need for the capability to analyze trends, megatrends and strategies, which influence the way of working more closely or more openly at any stage of the project in the innovation process and in the relationship with the innovation ecosystem according to the interviewees. As E2Na reports:

We may be looking for a technological solution in which France is more advanced, but the business area may be looking at Mexico and seeing how marketing leaders worked on the introduction of the same project, that is, open innovation is happening in all dimensions involved with innovation and at 360 degrees as well.

As Teece (2007) points out, the organization must detect a new technological or market opportunity, it must be capitalized through new products, processes, or services.

4.2.3 Cat3 - capability to map internal resources. This capability is identified as a way of mapping the competencies installed in the company. Thus, according to E23M, "it is necessary to have the ability to interpret the internal resources that it does or does not have, in addition to having the knowledge of its own organization and all its available resources, it must have the knowledge of its competence and seek new skills for innovation opportunities". As the E23M reports:

You have a specific project, software development, and we do not have the competence, but that is fundamental to the project, I will seek a partner to do this, you have a project schedule and the resources must be found. I realize that internally I do not have this competence, that is, neither $3 \mathrm{M}$ Brazil nor worldwide ( $3 \mathrm{M}$ world), so I look for it outside the organization.

E23M points out that "it is important to have this capability, because when you are looking for a partner in the network, there has been no previous experience".

These narratives support the statement of Dobelin and Galina (2019) that in sensing scanning, learning and interpretation activities are identified, which allows access to information and knowledge that can create opportunities.

After identifying these capabilities, we checked the transition of activities from sensing to seizing in the practice of open innovation and development of capabilities in this environment. The capabilities of establishing what to do openly (Cat4), mapping potential partners (Cat5) and establishing partners (Cat6) are reported as seizing activities.

4.2.4 Cat4 - capability to establish what to do openly. This capability emphasizes the way the company prepares and the ability to relate and to establish the models and advance initiatives with the ecosystem and combine it all internally and externally to succeed in open innovation.

In the definition of what to do openly, the interviewees pointed out the concern with contractual relationships. For E1Na, "it is necessary to take certain care in the establishment of an employment contract in open innovation, this requires a need to develop guidelines, clear policies, internal norms that facilitate the establishment of this partnership."

For E23M, the practice of open innovation includes the client, the perception of its curiosity that contributes to the definition of what to do openly. As exemplified by the interviewees:

The Brazilian market uses one type of packaging on the outside, one type of varnish, in Europe it is another one, in the United States it is another one, in Asia another one. So, in the same project you have to look at each of them in terms of open innovation, what are the characteristics of your market, your customer, you will ask the customer, and you will be his partner, you make the project dedicated to the customer (E23M). 
As Chesbrough (2012) and Bogers et al. (2018) point out, one way the company has used to bring these complements has been the practice of open innovation as a strategic alternative to gain competitive advantage through internal and external collaboration to identify opportunities and develop new ones.

4.2.5 Cat5 - capability of mapping potential partners. This capability arises from the moment the company has mapped, analyzed and defined trends. Based on such assumption, according to E2Na, "it has already been verified who is working with whom, who has filed the most patents, they begin to identify which are the potential partners who can later establish the partnership":

By understanding which resources and skills they have internally, from looking at the ecosystem to view external resources and capabilities, potential partners are identified to build a partnership strategy. Thus, it is necessary to have the ability to know where the partners are, which is this ability to map partners (E2Na).

For collaboration and partnership to occur, several forms of relationship and interaction must be developed in the innovation ecosystem with upstream and downstream supply providers and in networks, at open innovation events as mentioned by E23M below:

In the Tech Forum we join the technical community to discuss a particular subject. The goal was to bring in the big suppliers, great partners for them to show what they are working on in the future as well. In Tear Down we bring the product of the customer with a multifunctional team, multidisciplinary, and we disassemble the product that will signal several opportunities for innovation with the customer.

As Teece (2007) states, it is necessary for the organization to make investments to create strategies around investment decisions, set the time, increase the advantages of return and leverage products and services from one application to another.

4.2.6 Cat6 - capability to establish partnerships. This capability is considered relevant because the company must know who it is dealing with in the partnership, it needs to know ways of interaction, it needs to address a number of issues, such as intellectual property, financial plan and plan of work. According to E2Na:

In addition to having the ability to know where the partners are, which is the ability to map, it is also relevant to know how you interact with that partner, how you create this relationship, how you establish the partnership, how you deepen, see and draw paths that are more flexible to meet the needs of the company.

Regarding the relationship in the partnership, according to E2Na, "it occurs at various levels, it can start with an informal approach with the partner and can be a more institutional approach”. However, according to the interviewees E23M and E2Na, the establishment of the partnership entails respect and compliance to what was agreed and what is the value for each one involved. In a formalized way, the company must create the partnership and establish the type of relationship and interaction previously agreed on.

These reports corroborate the findings of Öberg and Alexander (2018), who highlight that the links among the levels in the organization are related to the search for relationships and collaboration, the market path and shared activities, with degrees of formalization and levels of knowledge among the actors. It is relevant to consider knowledge management criteria and management strategies in different dimensions of openness.

As Dobelin and Galina (2019) affirm, in the stage of seizing the companies seize what was obtained during sensing's activities and represent the company's responsiveness to the environment. 
INMR

18,2

Next, the transforming activities are identified in partnership implementation capabilities (Cat7), monitoring the interaction at two levels - technical, within the project and relational inside and outside the project (Cat8). Subsequently, we will identify the evaluation of the results stemming from the relationship with partners (Cat9).

4.2.7 Cat7 - capability to implement the partnership. This capability arises from the requirement of an integrative and strategic effort with all interfaces that interact internally and externally in the relationship with partners in the innovation ecosystem. For the respondent E23M, "this learning comes in practice and over time with an improvement that requires great effort when developing open innovation". This learning "arises from the relationship, how much the company can understand how things happen externally and bring them into the house" (E2Na). As reported:

It is much easier to evolve in some processes internally and learn from what is being done in the interaction, how much the company can absorb knowledge and improve the implementation internally. Always go to the next step and do not go back, and then you must go through it all over again $(\mathrm{E} 2 \mathrm{Na})$.

In transforming, the organization seeks continuous renewal, that is, transformation or change (Teece, 2007).

4.2.8 Cat8 - capability of monitoring Two-Level Interaction - Inside project and relational technician inside and outside project. This capability comprises the monitoring of interaction and relationship, it is the monitoring from the moment the partner is hired until the relationship begins to get established, as it happens with interaction in the project. Thus, according to E2Na, there are two levels of relationship, "one that is the technical level, that is inside the project, and the other is to see how the relationship among people and among institutions is". This understanding can be verified in the following report:

Monitoring the interaction is carried out in the relationship position and works as a condition when defining a project (E33M). This monitoring of interactions takes place when working with the provision of service, total outsourcing, buying from a partner, working with scientific cooperation with universities, etc. (E2Na).

In this context, organizational culture influences the way organizations operate in open innovation. According to E23M, "it is the culture that gives this strong foundation for open innovation to be present all the time in actions, it is an internalized thing that is already within the company's own culture". According to the E23M:

Our culture strengthens collaboration too much, we know and believe that innovation comes from collaboration and diversity, it affects the way open innovation is made, even internally. People have a huge predisposition to collaboration because of culture, it has the culture of $15 \%$ that lets you think of the new, the abstract, the completely different.

4.2.9 Cat9 - capability to evaluate the outcome of interaction and relationship in partnership. This capability is identified after establishing what is contracted and after monitoring the interaction or relationship in the partnership. Thus, according to the interviewees, in this relationship and interaction with the partner, it is important to evaluate the resources and capabilities involved, the knowledge and value generated in the partnership to define, or not, future partnerships. For E2Na:

[... .] as people get to know the company and its way of doing innovation, they get to know what it offers or can contribute to the process of collaboration with the different actors becoming a 
partner of choice, they understand that when something very relevant arises, people will look for a partner to develop the relationship.

In interaction and relationship with stakeholders, sustainability is an important factor in the organization. As E2Na reports:

When talking about partners or public institutions, you run into some limitations (policies and guidelines of each partner) and have to have flexibility, a power of evaluation, how far we want to go with that relationship.

In this context, transforming activity is identified in the routines and processes of the interviewees in Cat7, Cat8 and Cat9. According to Dobelin and Galina (2019), transforming activities aim at helping the organization to configure the organizational culture to accept high levels of internal change through decentralization and flexibilization and the implementation of modern techniques of human resources, knowledge management and learning mechanisms.

\subsection{Theoretical coding}

The theoretical codes and categories are integrative and outline the categories and focal codes gathered (Charmaz, 2009). Thus, the various routines and organizational processes of the companies were understood from the interviewees' reports in the coding stages that allowed relating capabilities in the practice of open innovation with the dynamic capabilities of sensing, seizing and transforming, according to Teece $(2007,2018)$.

To saturate the data of what we understood from the findings regarding the identification of capabilities in open innovation related to dynamic capabilities analyzed and discussed in the coding phase in the Section (4.2), we sought in this stage of theoretical codification to reinforce this understanding with the interviewees E3Na and E33M, respectively.

Noteworthy, as reported in the interview with E3Na:

I think that to understand the mapping capability you've identified, we do not call this part tracking interaction and relationship as mapping. Mapping to us is when you are mapping to establish, to delete. We do not use mapping for this other part. It's really a follow-up of the relationship, the interaction. Mapping for us comes in the beginning, it practically comes when you already know what you want to do, then you already have the strategic choice, and you start mapping who the potential partners are.

It is also relevant to transcribe a part of the interview carried out with participant E33M:

I identify our performance in all these capabilities in general. I cannot now think of the lack of any capability in this process of interaction with external partners. It seems to me that all of them are reported here. I cannot think of anything additional. They are somewhat fundamental to drive the kind of open innovation you want.

The abilities identified in this study and related to dynamic capabilities of sensing, seizing and transforming arise from the understanding of the company in its condition of contour in the ecosystem to talk, guide and discuss themes and models in the process of collaboration and partnership in the practice of open innovation. As discussed by Teece (2020), open innovation and dynamic capabilities reinforce one another. Thus, the relationship and interaction in partnerships are influenced by how much the company can have the capability of openness (Öberg \& Alexander, 2018) in the channels of communication and feedback for the improvement of ideas, development of hierarchies, routines and 
INMR 18,2

organizational processes at the management level and by the ability to orchestrate resources (Teece, 2007) or dynamic package (Peteraf et al., 2013).

In the practice of open innovation, cognitive and non-cognitive micro-foundations are developed (Nayak et al., 2019), and it is necessary to have knowledge management capability (Lichtenthaler \& Lichtenthaler, 2009) that triggers constant reformulation and superior performance in achieving competitive advantage (Teece, 2018). strengthening of dynamic capabilities. In this sense, it is necessary to develop strategic management capabilities of internal and external knowledge to obtain competitive advantage. This strategic management capability is understood as a dynamic capability that combines the strategic performance of the organization in the search and use of resources, competencies, technologies and value knowledge for processes and routines that arise from relationships, collaboration and interaction with stakeholders in the environment of open innovation.

This understanding corroborates the findings of Bulgacov and Takahashi (2019), who state that the appropriate combination between the organization's performance through processes and routines and its relationship with suppliers, customers and other actors in the environment is at the heart of the proposal of dynamic capabilities; and of Teece (2020), who states that open innovation enriches the company's knowledge base and its ability to detect and seize to transform the company's internal resources.

\section{Final considerations}

The general objective of this article was to answer the following research question "How do capabilities in the practice of open innovation relate to dynamic capabilities?". In the practice of open innovation carried out by the companies $3 \mathrm{M}$ of Brazil and Natura, we could identify nine capabilities that relate to the dynamic capabilities of sensing, seizing and transforming: Sensing (capabilities of mapping and updating trends in the market, analysis and definition of trends and strategies and mapping of internal resources); seizing (capability to establish what to do openly, to map potential partners and to establish partners); and transforming (capabilities related to partnership implementation, monitoring interaction at two levels: technical within the project and relational inside and outside the project and evaluation of the result of interaction and relationship in partnership).

This set of capabilities present in open innovation indicates the development of the dynamic capability to strategically manage internal and external knowledge. We identified that these combined capabilities are relevant in the configuration of routines, processes and internal and external relationships as a critical capability for the management of the company.

Our paper presents a few theoretical and practical contributions. It contributes to the evolution and consolidation of INMR's innovation literature, to the extent that it allows to understand the capabilities developed in the practice of open innovation, broadens discussions on dynamic capabilities (Teece, 2007, 2018, 2020), open innovation (Öberg \& Alexander, 2018; Bogers et al., 2019) and emphasizes internal and external knowledge management capabilities in the innovation process (Lichtenthaler \& Lichtenthaler, 2009).

The limitation of the study refers to the number of interviewees approached; therefore, our findings do not allow generalizations. However, the use of grounded theory through various data collection strategies in the interviews allowed the triangulation of data, increasing the credibility, validity and quality of the research.

We suggest for future studies to verify whether these capabilities in the practice of open innovation, related to dynamic capability, are understood by managers in organizations operating in different segments and with different sizes. 


\section{References}

3M (2016). O poder da colaboração. Disponível em available at: www.3minovacao.com.br/aprenda/ cursos/colaboração (Acesso 26 out. 2016).

Bogers, M., Chesbrough, H., \& Moedas, C. (2018). Open innovation: Research, practices, and policies. California Management Review, 60(2), 5-16. doi: https://doi.org/10.1177/0008125617745086.

Bogers, M., Chesbrough, H., Heaton, S., \& Teece, D. J. (2019). Strategic management of open innovation: A dynamic capabilities perspective. California Management Review, 62(1), 77-94. doi: https:// doi.org/10.1177/0008125619885150.

Bogers, M., Zobel, A. K., Afuah, A., Almirall, E., Brunswicker, S., Gawer, A., \& Ter Wal, A. L. J. (2016). The open innovation research landscape: Established perspectives and emerging themes across different levels of. Analysis. SSRN Electronic Journal, 24(1), 8-40, doi: https://doi.org/10.2139/ ssrn.2817865.

Bulgacov, S., \& Takahashi, A. R. W. (2019). Capacidades dinâmicas: Origem, evolução e microfundamentos do conceito In A. R. W. Takahashi, \& S. Bulgacov (Eds.), Capacidades dinâmicas e renovação estratégica: Como organizações se reinventam ao longo do tempo, Curitiba: Juruá Editora.

Charmaz, K. (2009). A construção da teoria fundamentada: Guia prático Para análise qualitativa, Tradução Joice Elias Costa. Porto Alegre: Artmed.

Chesbrough, H. (2012). Open innovation: Where we've been and where we're going. ResearchTechnology Management, 55(4), 20-27. doi: https://doi.org/10.5437/08956308X5504085.

Chesbrough, H., \& Bogers, M. (2014). Explicating open innovation: Clarifying an emerging paradigm for understanding innovation, Oxford: Oxford University Press. doi: https://doi.org/10.1093/acprof: oso/9780199682461.003.0001

Denford, J. S. (2013). Building knowledge: Developing a knowledge-based dynamic capabilities typology. Journal of Knowledge Management, 17(2), 175-194. doi: https://doi.org/10.1108/ 13673271311315150.

Dixon, S., Meyer, K., \& Day, M. (2014). Building dynamic capabilities of adaptation and innovation: A study of micro-foundations in a transition economy. Long Range Planning, 47(4), 186-205. doi: https://doi.org/10.1016/j.lrp.2013.08.011.

Dobelin, S., \& Galina, S. V. R. (2019). Desagregando as capacidades dinâmicas: Análise conceitual Para melhor compreensão de uma realidade. In A. R. W. Takahashi, \& S. Bulgacov, (Eds.) Capacidades dinâmicas e renovação estratégica: Como organizações se reinventam ao longo do tempo, Curitiba: Juruá Editora.

Eisenhardt, K. M., \& Martin, J. (2000). A. Dynamic capabilities: What are they? Strategic Management Journal, 21(10/11), 1105-1121, doi: https://doi.org/10.1002/1097-0266(200010/11).

Helfat, C. E., Finkelstein, S., Mitchell, W., Peteraf, M. A., Singh, H., Teece, D. J., \& Winter, S. G. (2007). Dynamic capabilities: Understanding strategic change in organizations, London: Blackwell.

Lichtenthaler, U., \& Lichtenthaler, E. (2009). A capability-based framework for open innovation: Complementing absorptive capability. Journal of Management Studies, 46(8), 1315-1338. doi: https://doi.org/10.1111/j.1467-6486.2009.00854.x.

Natura. (2016). Uma busca constante que promove o desenvolvimento dos indivíduos, da empresa e da sociedade. Disponível em www.natura.com.br/inovacao (Acesso em 26 out. 2016).

Nayak, A., Chia, R., \& Canales, J. I. (2019). Non-cognitive microfoundations: Understanding dynamic capabilities as idiosyncratically refined sensitivities and predispositions. Academy of Management Review, 45(2), 280-303. doi: https://doi.org/10.5465/amr.2016.0253.

Öberg, C., \& Alexander, A. T. (2018). The openness of open innovation in ecosystems - Integrating innovation and management literature on knowledge linkages. Journal of Innovation \& Knowledge, 4(4), 211-218. doi: https://doi.org/10.1016/j.jik.2017.10.005. 
INMR

18,2

Peris-Ortiz, M., Devece-Carañana, C. A., \& Navarro-Garcia, A. (2018). Organizational learning capability and open innovation. Management Decision, 56(6), 1217-1231. doi: https://doi.org/ 10.1108/MD-02-2017-0173.

Peteraf, M. A., Di Stefano, G., \& Verona, G. (2013). The elephant in the room of dynamic capabilities: Bringing two diverging conversations together. Strategic Management Journal, 34(12), 1389-1410. doi: https://doi.org/10.1002/smj.2078.

Teece, D. J. (2007). Explicating dynamic capabilities: The nature and microfoundations of (sustainable) enterprise performance. Strategic Management Journal, 28(13), 1319-1350. doi: https://doi.org/ 10.1002/smj.640.

Teece, D. J. (2018). Business models and dynamic capabilities. Long Range Planning, 51(1), 40-49. doi: https://doi.org/10.1016/j.lrp.2017.06.007.

Teece, D. J. (2020). Hand in glove: Open innovation and the dynamic capabilities framework. Strategic Management Review, 1(2), 233-253. doi: https://doi.org/10.1561/111.00000010.

Teece, D. J., Pisano, G., \& Shuen, A. (1997). Dynamic capabilities and strategic management. Strategic Management Journal, 18(7), 509-533. doi: https://doi.org/10.1002/(SICI)1097-0266(199708) 18:7<509::AID-SMJ882>3.0.CO;2-Z.

Tidd, J., \& Bessant, J. (2015). Gestão da inovação (5a ed.). Porto Alegre: Bookman.

Corresponding author

Edson Rodrigues de Aro can be contacted at: edsonaro@ufmt.br

For instructions on how to order reprints of this article, please visit our website: www.emeraldgrouppublishing.com/licensing/reprints.htm

Or contact us for further details: permissions@emeraldinsight.com 